\title{
Modalidad Deportiva de Salvamento y Socorrismo: Un Deporte que Educa en los Valores del Ideario Olímpico
}

\section{Lifesaving: A Sport that Teaches Values of the Olympic Ideology}

\author{
Ma Eugenia Martínez-Gorroño *, Ismael Sanz-Arribas y Ma Teresa Calle-Molina \\ Universidad Autónoma de Madrid, España
}

\section{DESCRIPTORES:}

Valores olímpicos

Carta olímpica

Real Federación

Española de

Salvamento y

Socorrismo

Educación

Pierre de Coubertin

RESUMEN:

El presente trabajo tiene como objetivo demostrar que la filosofía olímpica está presente en la realidad y la práctica del deporte actual, concretamente en la modalidad deportiva que desarrolla la Real Federación Española de Salvamento y Socorrismo (RFESS). El diseño metodológico ha partido de la identificación y categorización de los documentos que podrían ser fuentes primarias. Por un lado, la documentación escrita por Pierre de Coubertin en la que fue perfilando el ideario olímpico, y, por otro, la documentación correspondiente a los objetivos y directrices del funcionamiento de la RFESS. Tras su análisis documental se procedió a la identificación y al examen del paralelismo que mantiene la filosofía de la génesis del olimpismo con las intenciones y objetivos de la práctica deportiva impulsada por esta federación. Como resultado, se exponen las sinergias y las reflexiones en torno a los paralelismos encontrados, tanto en los planeamientos que a priori estuvieron en la creación del Movimiento Olímpico y la RFESS, como en la realidad de sus circunstancias actuales. Se proponen alternativas y respuestas que, presentes en la praxis de la RFESS, deben ser tenidas en cuenta en todas las prácticas deportivas actuales, para compensar otras aportaciones menos constructivas que muestran ciertos medios de comunicación.
\end{abstract}

\section{KEYWORDS:}

Olympic values

Olympic chapter

Royal Spanish

Lifesaving Federation

Education

Pierre de Coubertin

\section{ABSTRACT:}

The present work seeks to demonstrate that the Olympic philosophy is present in the reality and practice of sport today, specifically in the objectives and practice developed by the Royal Spanish Lifesaving Federation (RSLF). The methodological design has started from the identification and categorization of the documents that could be primary sources. On the one hand, the documentation written by Pierre de Coubertin in which he outlined the Olympic ideology, on the other hand, the documentation corresponding to the objectives and guidelines of the operation of the RSLF. After its documentary analysis, we proceeded to identify and examine the parallelism that maintains the philosophy of the genesis of Olympism with the intentions, objectives and purposes of the sports practice promoted by this federation. As a result, the synergies and reflections on the parallels found both in the planning that was present in the creation of the Olympic Movement and the RSLF, and in the reality of their current circumstances, are presented. It proposes alternatives and responses that are present in the practice of RSLF and that should be considered in all current sports practices, in order to compensate for other less constructive contributions shown by certain media.

CÓMO CITAR:

Martínez-Gorroño, M. E., Sanz-Arribas, I. y Calle-Molina, M. T. (2021). Modalidad deportiva de salvamento y socorrismo: Un deporte que educa en los valores del ideario olímpico. Revista Internacional de Educación para la Justicia Social, 10(1), 127-144.

https://doi.org/10.15366/riejs2021.10.1.008

*Contacto: ismael.sanz@uam.es

ISSN: 2254-3139

revistas.uam.es/riejs 


\section{Introducción y antecedentes}

Este trabajo es el resultado parcial de una línea de investigación que desarrolla un equipo de docentes que forma parte del Comité Juego Limpio, entidad integrada en el Centro de Estudios Olímpicos de la Universidad Autónoma de Madrid (UAM). Este equipo centra una de sus líneas de investigación en el ideario olímpico y en la búsqueda de su presencia en la realidad y la práctica del deporte actual, a fin de evidenciar la calidad y buen hacer de deportistas y entornos deportivos, frente a una realidad mediática que parece contradecir la contribución positiva que el deporte supone en las sociedades actuales.

El deporte en la actualidad es una manifestación cultural universalizada y globalizada. Está presente en las formas expresivas de grupos sociales y de colectivos de todo el planeta (Martínez-de-Haro, Sanz-Arribas y Álvarez-Barrios, 2019). El Movimiento Olímpico, desde su fundación a partir de los impulsos de Pierre de Coubertin, ha contribuido definitivamente a que el deporte se haya convertido en un fenómeno social multitudinario. Según los datos de Radiotelevisión Española, más de 36,5 millones de espectadores vieron en algún momento los Juegos Olímpicos de Pekín. En Río-2016, la plataforma de vídeos del Comité Olímpico Internacional sumó más de nueve millones de horas en contenidos consumidos por los casi un millón de usuarios únicos que diariamente visitaban su portal. La web oficial tuvo más de 26 millones de visitas durante las dos semanas de los Juegos, más del doble que en Londres-2012 (EP, 2008; Palco23, 2016).

Pero el deporte olímpico, desde el ideario de su creador, ha pretendido mantener y transmitir aptitudes y valores que no siempre están presentes en las competiciones que hoy tenemos oportunidad de ver. Sin embargo, el Movimiento Olímpico sigue manteniendo los mismos objetivos que motivaron a su creador. En la Carta Olímpica actual, puede leerse: "el Movimiento Olímpico tiene como objetivo contribuir a la construcción de un mundo mejor y más pacífico, educando a la juventud a través de una práctica deportiva conforme con el Olimpismo y sus valores” (COI, 2019, p. 17)

Las potencialidades educativas y de transmisión de valores positivos que puede proporcionar el deporte, conllevaron hace décadas su inclusión como instrumento educativo en las asignaturas obligatorias escolares de un gran número de países. Esta potencialidad educativa ha sido reflexionada por múltiples especialistas como Hernández Álvarez (1994) quien exponiendo las funciones que la actividad física y el deporte han cumplido a lo largo de la historia, mencionaba "la función de conocimiento", que ha desempeñado y desempeña como Educación Física escolar:

El movimiento es uno de los instrumentos cognitivos fundamentales de la persona, tanto para conocerse a si misma como para explorary estructurar su entorno inmediato. Por medio de la organización de sus percepciones sensomotrices toma conciencia de su propio cuerpo y del mundo que le rodea. (Hernández Álvarez, 1994, p. 76)

Otros inquietos personajes históricos reflexionaron también sobre el poder educativo del deporte como Pierre de Fredy, Barón de Coubertin. Él dedicó su vida y su fortuna en su empeño filantrópico por solventar los problemas de su tiempo para lo que vio en el deporte un instrumento ideal, siempre que fuera orientado adecuadamente. Fundó el Movimiento Olímpico, institución con la que pretendía fomentar la práctica deportiva realizada en base al código de valores que supone la filosofía olímpica y que denominó "Olimpismo". Actualmente, el Olimpismo viene definido en la Carta Olímpica como:

Una filosofía de vida, que exalta y combina en un conjunto armónico las cualidades del cuerpo, la voluntad y el espíritu. Al asociar el deporte con la cultura y la educación, el Olimpismo se propone crear un estilo de vida basado en la alegría del esfuerzo, el valor educativo del buen ejemplo, la responsabilidad social y el respeto por los principios éticos fundamentales universales. (COI, 2019, p. 11)

Esta definición resume el ideario que Coubertin fue gestando hasta conformar la "filosofía olímpica" cuyos principios fue exponiendo en sus escritos y conferencias. Principios y orientaciones que hemos procedido a localizar en la documentación que ha sido fuente primaria para este trabajo. Son aquellos documentos en los que expuso sus objetivos para la creación del Movimiento Olímpico, de los que citaremos posteriormente algunos fragmentos. 
A pesar de las potencialidades educativas que la práctica deportiva tiene implícitas; en la realidad actual, fuera de las aulas (aunque puntualmente también dentro de ellas), el deporte no siempre presenta esta característica positiva y constructiva. Como fruto de las manipulaciones y de la escala de valores tergiversada que se nos va imponiendo, se producen cotidianamente con demasiada frecuencia, conductas "antideportivas" agresivas e irrespetuosas, tanto por parte de los deportistas, como hacia ellos, hacía los árbitros, etc. Estas conductas bajo el lema "el fin justifica los medios" se admiten en pro de la búsqueda de la victoria deportiva, mostrada como el valor prioritario y fundamental ante el cual, los derechos o principios fundamentales de las personas quedan en un segundo plano. Este aspecto, dada la gran presencia de ciertas competiciones deportivas en los medios de comunicación y en la cotidianeidad de todos, está suponiendo una influencia nada educativa para jóvenes deportistas, y espectadores, influyendo en los comportamientos de ciertos colectivos, que parecen olvidar la escala de valores marcada por los "principios fundamentales y universales" (COI, 2019, p. 11) que deben regir la convivencia.

La evolución del tipo de práctica deportiva que con mayor frecuencia emiten los medios de comunicación, nos condicionó a averiguar si la práctica deportiva orientada a partir de esos principios que supone la filosofía del olimpismo está presente en el deporte que hoy en día se practica y se fomenta. Comenzando con lo que metodológicamente se conoce en la investigación como "aproximación al objeto de estudio" analizamos el contenido de un documento de la RFESS publicado bajo el título "Misión, visión y valores de la Real Federación Española de Salvamento y Socorrismo". Ya en su primer epígrafe, en el que declara su Misión, detectamos su consonancia y afinidad con los Principios Fundamentales del Ideario Olímpico.
...vela por la protección de la salud de las personas que practican su deporte, el juego limpio $y$ la dimensión ética de la competición; fomenta la formación en materias relacionadas con los primeros auxilios, el salvamento y el rescate; impulsa la cultura de la prevención de los accidentes en el medio acuático y de la preservación de la vida en situaciones de riesgo a tra- vés de la cultura del salvamento; $y$ promueve la capacitación de las personas en la esfera del socorrismo. (RFESS, 2020a, p. 1)

Al constatar esta sinergia, centramos pues el objetivo de este trabajo en demostrar la presencia del ideario olímpico en las actividades que desarrolla la RFESS y la modalidad deportiva del Salvamento y Socorrismo. Con ello, igualmente intentamos compensar la falta de investigaciones que hemos constatado en cuanto a conocer la presencia del ideario olímpico en la realidad del deporte actual. Apenas algunos de nuestros trabajos se han centrado en indagar su presencia en la realidad escolar de nuestro país (Calle-Molina y Martínez Gorroño, 2014).

\section{Método}

El presente trabajo se ha desarrollado con una metodología de investigación de tipo histórico y cualitativo. Partiendo de las potenciales fuentes que supone la ingente obra escrita de Pierre de Coubertin ${ }^{1}$, identificamos y categorizamos como fuentes, un grupo de ellas que contienen información concreta sobre el ideario que pretendía otorgar al Movimiento Olímpico, especificadas en el apartado final como fuentes primarias, y que, por tanto, contienen datos sobre la filosofía y el ideario que trataba de conferir al Movimiento Olímpico que fue gestando. Organizamos y clasificamos las mismas como fuentes primarias, agrupándolas por grupos temáticos o categorías, desde una estructura conceptual de los valores en ella contenidos. Se realizó un análisis documental de la actual Carta Olímpica bajo la misma perspectiva, para extraer la orientación que dicha filosofía olímpica mantiene en el ideario del Movimiento Olímpico actual. Por otra parte, tras localizar las fuentes primarias que contenían las bases de la creación, los objetivos y prácticas de la RFESS, y someterlas al mismo análisis documental, se realizó un trabajo de contraste y comparación. Como resultado, se ofrecen los análisis de las sinergias, similitudes y paralelismos entre ambos planteamientos: los propósitos y la filosofía del ideario

\footnotetext{
${ }^{1}$ La obra escrita de Pierre de Coubertin ha sido evaluada por el Comité Olímpico Internacional y estima que consta de unas quince mil páginas impresas.
} 
coubertiniano y los planteamientos, objetivos y prácticas de la RFESS, partiendo de que el instrumento común de dichas instituciones son las prácticas deportivas con una orientación solidaria, filantrópica y con una disposición clara de servicio al colectivo social y a la humanidad.

\section{El deporte como elemento y contenido de la educación para formar en la responsabilidad social, la generosidad y la cooperación}

\subsection{El deporte como instrumento educativo}

Tras una aproximación superficial a los principios del Movimiento Olímpico, puede parecer que el deporte olímpico es una actividad física sistemática cuyo objetivo es lo que Hernández Álvarez (1996) denomina como "función anatómico-funcional", es decir, "cuando la actividad física se usa para completar el desarrollo de las capacidades motrices del individuo de forma utilitaria, como preparación para la mejora del rendimiento físico" (p. 75). Así, la práctica deportiva parece solo orientada para conseguir cumplir ese lema de Citius, altius, fortius, que Coubertin, con palabras de Henri Didon, convirtió en lema Olímpico.

Sin embargo, los documentos que contienen la orientación que Coubertin quería conferir a la institución que deseaba crear: el Movimiento Olímpico, evidencian una orientación educativa. Pretendía una reforma social introduciendo como instrumento educativo el deporte, en las cotidianeidades de los europeos; tanto en la etapa educativa, en los centros escolares, como en las aficiones cotidianas de los diferentes grupos sociales (Martínez-Gorroño y Hernández-Álvarez, 2014). El deporte incorporado personal y voluntariamente para enfocar la vida como un proceso de superación personal en el que cada uno se impone sus propios retos: más veloz, más alto, más fuerte, teniendo en cuenta la amplitud que implica la metáfora.

A aquella reforma social con base educativa hacía referencia, por ejemplo, cuando en 1888 remitió una carta a la Sociedad de Economía Social solicitando su apoyo para crear la "Asociación para la Reforma de la Educación Escolar en Francia” que se materializó en 1889. Reforma que planteó antes que la creación de los Juegos Olímpicos en 1894, orientada a los adultos y a todos los colectivos sociales (Martínez-Gorroño y Hernández-Álvarez, 2014). En ella escribía:

Hay que hacer la reforma social a través de la educación. No hay que trabajar con los adultos, sino con los niños, preparar su triunfo proporcionándoles las cualidades que les harán aptos para comprender, y las cualidades de carácter idóneas para ejecutar la transformación, poniendo el ejercicio físico como contrapeso a la fatiga intelectual [...] [intentando] que en la educación entren, mediante el deporte, nuevos principios de disciplina y de responsabilidad. (Coubertin, 1888, citado en Martínez-Gorroño y Hernández-Álvarez, 2014, p. 67)

Muchos fueron los argumentos para convencer a los responsables educativos de las ventajas de introducir el deporte como elemento educador y parte de la materia que con el tiempo se llamaría Educación Física, cuyo contenido en aquellos momentos era la gimnasia. Si bien el argumento textual del párrafo siguiente queda actualmente algo devaluado por todos los resultados de las investigaciones fisiológicas que hoy disfrutamos; por otro lado, su contenido alcanza una especial nueva vigencia, para los colectivos urbanos y sedentarios cuyo carácter se va manipulando, para que se sienta atraído e inclinado a compartir solamente con aquellos que tienen apetencias afines a las suyas. Así, Coubertin argumentaba que el ejercicio físico es un agente de compensación orgánica y también es creador de fuerza moral y nacional:

Aporta a la existencia demasiado sedentaria o demasiado cerebral del adolescente o del hombre el contrapeso de los movimientos moderados y dosificados convenientemente [...] El ejercicio físico, concebido y aplicado de cierto modo, puede contribuir a forjar el carácter a revigorizar una colectividad, e, incluso en tiempos de democracia, a servir de unión entre las diferentes clases sociales. (Coubertin, 1918, p. 1) 
Muchos años mantuvo Coubertin sus esfuerzos por la reforma educativa que implicaba la introducción del deporte debidamente orientado. En 1925, en su discurso en el Ayuntamiento de Praga, afirmaba:

Ha llegado el momento de elevar un edificio pedagógico, cuya arquitectura sea más apropiada a las necesidades de la época. [Yo] he emprendido la obra nueva con el espiritu deportivo, es decir, con la alegría del esfuerzo, el gusto por el riesgo y el culto al ideal desinteresado. (Coubertin, 1925, p. 551)

El deporte como elemento y contenido educativo que defendió Coubertin puede verse presente y vivo en nuestra realidad en la Real Federación Española de Salvamento y Socorrismo. Está específicamente explícito; con solo acceder a su web oficial. En ella, consta, como apartado de los valores, que esta Federación "coloca a la formación como eje vertebrador de su afán diario para el enriquecimiento y desarrollo de la persona...” (RFESS, 2020a, p. 2).

Y, bajo el epígrafe de la "visión" de esta Federación, puede leerse:

La RFESS basa el desarrollo de sus trabajos en los principios de eficacia, eficiencia, economía, viabilidad, crédito y reputación, persiguiendo la formación integral de la persona deportista desde la más temprana edad y el respeto a la convivencia y las normas. (RFESS, 2020a, p. 1)

En su "misión", se deja constancia de sus objetivos y actividades:

...fomenta la formación en materias relacionadas con los primeros auxilios, el salvamento y el rescate; impulsa la cultura de la prevención de los accidentes en el medio acuático y de la preservación de la vida en situaciones de riesgo a través de la cultura del salvamento; $y$ promueve la capacitación de las personas en la esfera del socorrismo. (RFESS, 2020a, p. 1)

Podemos afirmar que la RFESS ostenta, mantiene y promociona en su realidad, prácticas y objetivos actuales, el testigo que Coubertin impulsó durante muchos años en cuanto a utilizar el deporte como instrumento para la educación. Esta Federación es una realidad viva de la vigencia en el deporte del ideario coubertiniano y confirma su puesta en práctica en la actualidad. Desarrolla en sus prácticas su misma idea e impulso en cuanto a utilizar el deporte como un elemento educativo para la formación de las personas y por ello, igualmente manifiesta que debe estar presente desde temprana edad, para formar en el respeto y la aceptación de las normas que deben presidir la convivencia de todo colectivo social que pretenda vivir en armonía.

Estos aspectos que cumple y desempeña la modalidad deportiva del Salvamento y Socorrismo en nuestra sociedad llevan a algunos autores a conclusiones similares con respecto a la introducción de este deporte como contenido de la educación actual. Así, Angueira (1998) considera que el gran elemento diferenciador de este deporte y, lo que le convierte en único en la formación escolar y extraescolar, es su carácter humanitario.

Los apartados siguientes pormenorizan otros muchos aspectos que muestran cómo la RFESS pone en práctica, materializa y es una continuidad viva de las ideas de aquel humanista, Pierre de Coubertin, cuyos esfuerzos vitales impulsaron los valores que hoy identificamos como Filosofía Olímpica y Olimpismo.

Sin embargo, los datos históricos de los antecedentes de esta federación tienen sus raíces en similares impulsos a los que movieron a Coubertin. Es decir, surgieron a partir de ciertos sectores y grupos sociales solidarios y filantrópicos preocupados por el interés de toda la humanidad, y que, en su caso, tienen incluso algunas fechas anteriores a los logros coubertinianos. Así, la primera competición internacional oficial documentada de entonces denominado Salvamento y Socorrismo se celebró, según Sánchez Fernández (2007), en Marsella, en 1878, fecha considerada como la creación del embrión de lo que más tarde, a partir de 1910, dio lugar a la FIS (Fédération Internationale de Sauvetage Aquatique), que quedó formalmente constituida en aquella lejana fecha, hace ya más de 100 años. 


\subsection{La cooperación, la solidaridad y la responsabilidad social: Ideas, impulsos y obje- tivos comunes}

La cooperación de los individuos particulares como forma de responsabilidad social para con los miembros de su colectividad, la analizó Coubertin como una necesidad imprescindible para la convivencia y el avance de las sociedades que sean solidarias y democráticas.

En 1901 Coubertin escribía:

Cualesquiera que sean los gobiernos de una democracia, esta necesita de cooperación para vivir y prosperar [...] y ésta necesita ser aprendida, y se lleva mucho ganado si se aprende desde la juventud. Esta verdad se impondrá en la democracia, la cual se verá obligada a introducir la cooperación en la vida escolar para preparar a los futuros ciudadanos con vista a la vida activa. (Coubertin, 1901, p. 142)

En este mismo documento, también hacía referencia a la necesidad de la toma de conciencia por parte de las personas sobre su compromiso con los grupos humanos a los que pertenecen y a los que deben su realidad. Señalaba, como en múltiples ocasiones, la necesidad de cooperación y la responsabilidad social que debía ser adquirida desde la etapa escolar.

En una sociedad democrática, el hábito de cooperación es imprescindible. El ciudadano útil para la democracia será el que entre en la vida activa entrenado ya al esfuerzo colectivo, acostumbrado inconscientemente a los movimientos, al ritmo y a la contención que este esfuerzo exige. (Coubertin, 1901, p. 142)

En la actualidad, "la responsabilidad social" podemos encontrarla explícitamente citada también en la definición del Olimpismo de la Carta Olímpica: "el Olimpismo se propone crear un estilo de vida basado en la alegría del esfuerzo, el valor educativo del buen ejemplo, la responsabilidad social...” (COI, 2019, p. 11).

Este planteamiento sobre la cooperación de los individuos, apelando a la responsabilidad social de todos los miembros de un colectivo, es el mismo punto de partida que se aprecia en el impulso del que partió la creación de la Real Federación Española de Salvamento y Socorrismo. Fue creada en 1961 con el objetivo de utilizar como elemento e instrumento, cierta forma de deporte, en beneficio de cualquier otro miembro del colectivo que lo precise: un bien común. Solamente el concepto del que parte el objetivo de su constitución ya implica un enfoque de inquietudes solidarias y contribución social que tienen una sinergia definitiva con los planteamientos de Pierre de Fredy.

En su declaración de principios, bajo el título: “Misión, visión y valores de la Real Federación Española de Salvamento y Socorrismo" puede leerse:

La RFESS asume la responsabilidad de gestionar una modalidad deportiva que salva vidas, un deporte cuyo origen es la solidaridad entre los seres humanos, y extiende su proyección a la preservación de la vida humana a través de su intervención para la dotación de la persona de los conocimientos básicos para alcanzar la capacidad de discernir en la prevención de los accidentes que la ponen en peligro y dotarla de las nociones necesarias para actuar en caso de necesidad para salvaguardarla. (RFESS, 2020a, p. 1)

La RFESS se encarga de promocionar esta modalidad deportiva a nivel estatal, dependiendo de ella las diversas federaciones autonómicas, que promocionan e inculcan el deporte en su radio de acción.

En sus Estatutos la RFESS hace constar que es una: "entidad asociativa, sin ánimo de lucro...de carácter privado y configuración legal, dedicada a la promoción, práctica y desarrollo del Salvamento y Socorrismo...” y se ubica a sí misma como: “Agente colaborador de la Administración Pública” (RFESS, 2016, p. 1). Claramente, la cooperación está en su punto de partida. Su objetivo es impulsar y orientar como actividad deportiva (elevándola a categoría de deporte), unas destrezas que el deportista realizaría en beneficio de otros, colaborando por propia iniciativa en la obligación que todas las Administraciones Públicas tienen con los ciudadanos en cuanto a prestarles ayuda y auxilio para conservar la integridad y la salud.

La perspectiva de esta federación y su modalidad deportiva es sin duda singular y única. Las actividades que realizan los deportistas que ella acoge e impulsa, no tienen como objetivo final su propio beneficio. 
El objetivo final de su preparación física, técnica y táctica, no son ellos mismos, como sucede en otros deportes; su victoria es el beneficio de otros. Cuanto más competentes son en este deporte, más eficaces son para salvar la vida de otras personas. Para ello, libremente desarrollan su físico, realizan sus entrenamientos y orientan su esfuerzo y su voluntad. Y todo ello es "convertido" y orientado como una actividad deportiva, que hoy se conoce como modalidad deportiva de Salvamento y Socorrismo. Al margen de las ideas presentadas en el documento "Misión, visión y valores de la Real Federación Española de Salvamento y Socorrismo", otros autores especialistas igualmente han considerado que esta modalidad deportiva posee un carácter solidario, caritativo, humanitario y, que, incluso dispone de una gran capacidad para educar en valores útiles para la humanidad que se corresponden con la acción de salvar vidas de forma desinteresada (Abraldes, 2004; O'Farril, 1971; Palacios y Paredes, 1992; Sánchez Fernández, 2007).

Este planteamiento para la creación de una Federación deportiva suscita una especial reflexión por su singularidad. Actualmente, esta federación bien podría identificarse con otro tipo de institución declarada de interés público, integrada por voluntarios dispuestos a ayudar a quien lo necesite en momentos en los que su salud y su vida peligran. Lo singular también, es que, esas actividades que para ello se precisan, se decida convertirlas en deporte. Idéntica orientación con la que Coubertin quería instrumentalizar el deporte para que fuera un elemento para el bien común.

Ambos, Coubertin y la RFESS tuvieron como objetivo convertir las actividades y habilidades físicas en una forma de deporte, para hacerlas una contribución social. En el caso de la perspectiva de la citada Federación, parte de concebir como forma de práctica deportiva, la preparación de personas cuyo objetivo es salvar y socorrer a los demás en momentos críticos. Momentos en los que solamente una persona ajena puede aportar una colaboración a quien se encuentra en momentos de urgencia o accidente. Ayuda y colaboración que no puede llevar a cabo la propia persona en su propio beneficio.

En este sentido podemos leer en un Programa de formación de socorristas acuáticos como objetivo número 2 la siguiente información:

\begin{abstract}
Aumentar la seguridad en las instalaciones acuáticas, incrementando el número de personas capacitadas para desarrollar con eficacia las medidas de prevención adecuadas y de afrontar, en caso necesario, las situaciones de urgencia o emergencia que puedan presentarse durante el uso y disfrute del medio acuático en actividades deportivo-recreativas o de cualquier otro tipo, todo ello con la suficiente garantía de seguridad para las personas socorridas y los propios proveedores de la asistencia. (FSSCLM, 2017, p. 4)
\end{abstract}

Como ejemplo de los efectos y logros cotidianos que se suceden como consecuencia de las actividades de esta RFESS, en el párrafo siguiente, reproducimos un Comunicado de la Federación de Salvamento y Socorrismo de Canarias a la Federación de Salvamento y Socorrismo de Castilla y León en julio de 2000. Queda patente, a través de los efectos de las actividades de esta federación, la praxis de la idea coubertiniana de convertir al deporte en una contribución social:

Los hermanos Michael y Richard Rodríguez Mccullough, de 13 y 11 años de edad, pertenecientes a las categorías inferiores de Salvamento Acuático del Club Natación Martianez realizaron el rescate de un niño valenciano de 6 años, que se encontraba en peligro de ahogamiento, el pasado lunes día 3 de julio en una playa de Benicasim (Valencia). El hecho ocurrió el pasado lunes día 3 de julio, Michael y Richard, que se encuentran veraneando en la localidad Valenciana de Benicasim, estaban bañándose en la playa cuando observaron que un niño de corta edad, debido al estado del mar y que prácticamente no sabía nadar, se encontraba en peligro de ahogamiento por lo que Richard, ayudado por su hermano Michael acudieron en su ayuda rescatándolo del agua y trasladándolo hasta un lugar seguro, salvando así su vida. (Yanes Vega, 2000c, p. 1)

Los ciudadanos de a pie que crearon la RFESS personificaban sin duda el tipo de ciudadano que Coubertin exponía como necesario para dar respuesta a las necesidades sociales:

Tengo que exponer el tipo de ciudadano que necesitamos en Francia [...]. Queremos hombres que piensen por si mismos e independientes, que no miren al Estado como un bebé que mira a su madre, que no tengan miedo de tener que labrarse su propio camino en la vida. (Coubertin, 1889, p. 129) 
Y así los creadores de la RFESS (en aquel entonces FESS ${ }^{2}$ ) organizaron, por propia iniciativa, una institución que marca un camino para fomentar una modalidad deportiva para cooperar voluntariamente al entrenamiento de personas que quieran realizar las actividades físicas necesarias para ayudar a los que están en peligro y requieren auxilio. Independientemente de que el Estado tenga el deber de auxiliar y socorrer a los ciudadanos, el grupo, que constituyó la RFESS ha instituido un camino para contribuir a esta necesidad social. Por otra parte, en su forma de estructurarlo, personifica y comparte en la praxis, no solo la idea de la cooperación y la responsabilidad social, sino la forma asociativa que también señaló como imprescindible Coubertin:

En la sociedad democrática, el hábito de la asociación es el origen de toda fuerza útily la base de todo esfuerzo lógico...y a sea que los ciudadanos se asocien para unir esfuerzos o para combinar su capacidad de resistencia, ya para tascar el freno o empujar la rueda. (Coubertin, 1901, p. 140)

Y coincidiendo con otros aspectos, como son la reforma social que subyacía en los impulsos educativos de Coubertin, ya señalada, podemos afirmar que en la RFESS se hacen realidad otras de sus afirmaciones: "la solidaridad puede dar lugar a agrupaciones de un elevado alcance pedagógico” (Coubertin, 1901, p. 144). Esta federación evidencia unos objetivos y alcances pedagógicos de gran interés social que parte de una herencia de gentes de buen hacer y calidad humana, que hoy se materializa y está presente en el deporte que se practica en nuestro país.

Con la misma idea coubertiniana, redundando sobre el potencial educativo del deporte orientado adecuadamente, recogemos en el siguiente apartado las reflexiones de otro español contemporáneo, Palacios (1999), quién resalta el especial valor educador de la modalidad deportiva de Salvamento y Socorrismo:

Todos los deportes son válidos para lograr una formación más completa de la persona. Algunos son imprescindibles para conseguir esta formación. Y otros, no sólo cumplen con este propósito, sino que además aportan una serie de experiencias y conocimientos que son de enorme utilidad para nuestra vida y la de los demás. El salvamento deportivo, ese gran desconocido, pertenece a este último grupo de deportes. (Palacios, 1999, p. 82)

\subsection{El esfuerzo libre y voluntario y el ideal desinteresado}

Las formas y la orientación que el deporte debía tener para que pudiera ser calificado como "olímpico" conllevó muchos esfuerzos en las definiciones de Coubertin. Quería orientar y ampliar el contenido simplista que en forma superficial puede observarse en los deportes a partir de lo que Hernández Álvarez (1996) calificó como su "función agonista" y que podría definirse como un esfuerzo físico en pro de ser más veloz, más fuerte o saltar o lanzar más alto o más lejos.

El aspecto de que el deporte fuera una actividad adoptada voluntariamente por las personas para introducirla en sus cotidianeidades como instrumento para su propia y voluntaria superación, fue observado por Coubertin como la potencialidad fabulosa que debía ser transmitida desde la infancia. Por eso, debía introducirse como práctica educativa en la cotidianeidad escolar:

La voluntad, esto es lo que hace fecundo el deporte y lo transforma en un maravilloso instrumento [...] cultivar el esfuerzo por el esfuerzo, buscar obstáculos, ponerlos él mismo en el camino, mirar siempre un poco más lejos del punto que quiere alcanzar. Esto es lo que expresa muy bien la divisa elegida por el Padre Didon para sus alumnos de Arcueil3, reunidos en una asociación atlética: Citius, Altius, Fortius, más rápido, más alto, más fuerte. (Coubertin, 1901, p. 138)

En 1889, cuando se esforzaba por explicar lo que el deporte, dentro del olimpismo debía ser, para convertirse en un servicio a la sociedad, escribía:

\footnotetext{
${ }^{2}$ El 31 de marzo de 2011 le fue concedido el título de “Real” a la Federación Española de Salvamento y Socorrismo por parte de la Casa Real Española (RFESS, 2020b).

${ }^{3}$ Fue el primer centro docente que introdujo la reforma educativa que proponía Coubertin y que implicaba sustituir la gimnasia por el deporte y los juegos deportivos.
} 
El deporte se define por sus resultados: el esfuerzo libre, la lucha, la capacidad de sufrimiento, la cultura muscular del cuerpo y del carácter..., y su acción en la inteligencia [...] son los efectos de esos ejercicios en los que a veces hay que tomar decisiones rápidas e incluso correr peligros y compromisos, que necesitan tanta viveza en la reflexión, cuanta sangre fría en su ejecución. (Coubertin, 1889, p. 15)

Partiendo de estos análisis coubertinianos podemos ver su presencia en la generosidad de los deportistas que se acogen y se organizan en la RFESS. La mayoría de las pruebas físicas establecidas en el reglamento internacional de esta modalidad deportiva (ILS, 2019), simulan el rescate de personas que se encuentran en peligro dentro del agua, en una playa o en una piscina, como se muestra en las Figuras 1 y 2 . Estas pruebas, exponen a los deportistas a simulacros de rescate, en los que, a pesar de desarrollarse en un contexto controlado, siempre existe la posibilidad de que sus deportistas resuelvan estos retos de forma audaz e ingeniosa, provocando la mejora de su capacidad para resolver problemas en el entorno acuático con los que pueden encontrarse en su vida cotidiana o incluso, laboral. Todo ello, evidencia no solo su generosidad y su compromiso social; sino, además, y redundando en la idea de que sea además hecho por propia voluntad, evidencia la puesta en práctica hoy en día de esos "esfuerzos libres" mencionados por Coubertin.

Figura 1

Prueba física establecida por la RFESS simulando el rescate de una persona en una playa
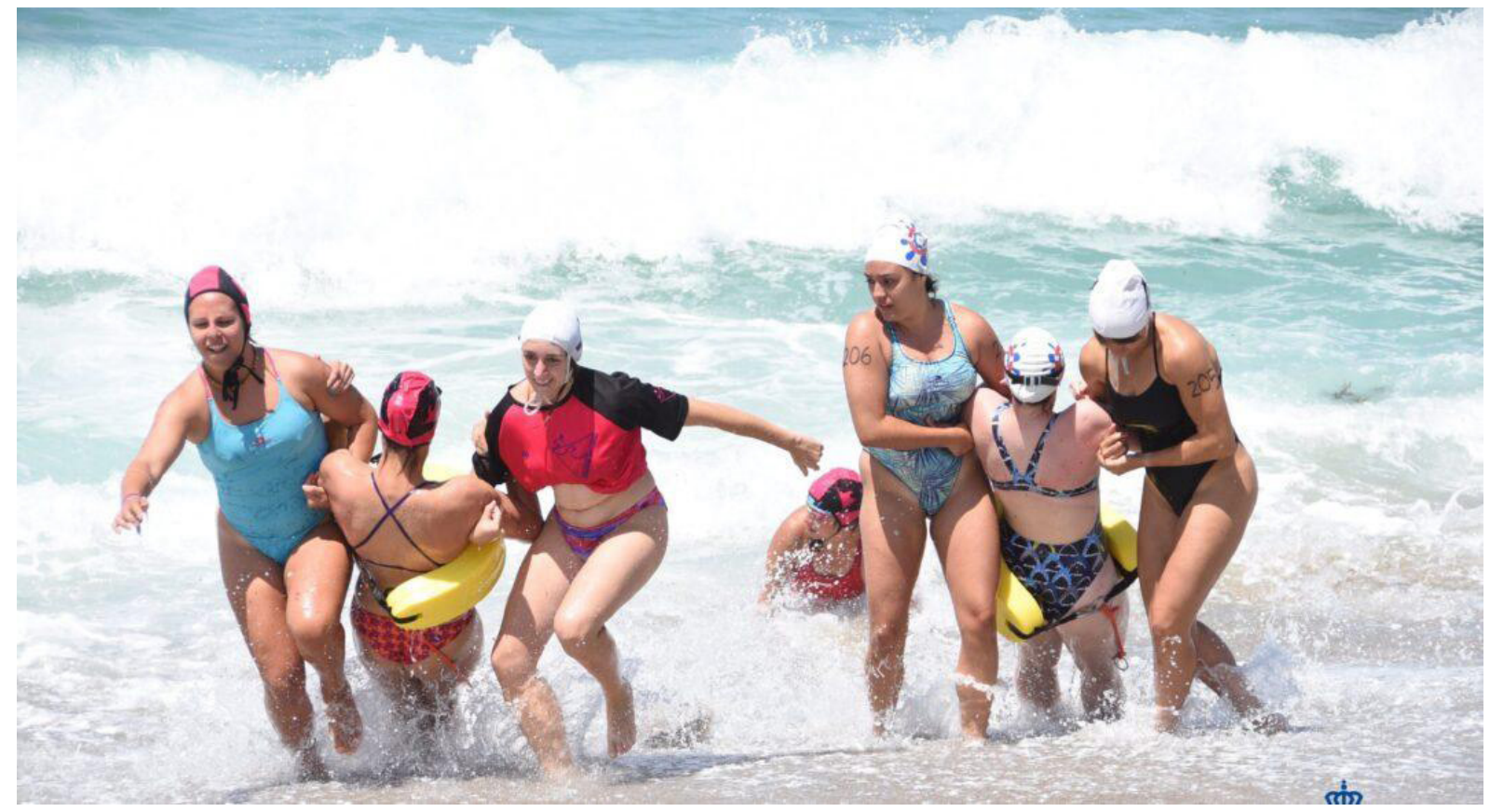

Nota. Fotografía cedida por la RFESS.

En 1993, los autores Cocu y Pelayo reflexionaban sobre las específicas características de esta modalidad deportiva, que la diferencian de otros deportes orientados a la superación desde la perspectiva de la "función anatómico-funcional" de Hernández Álvarez (1996) ya mencionada. Afirmaban que la aparición del entonces denominado Salvamento Deportivo es lógica y consecuencia de la natación, puesto que:

El fin de la natación no es hacer competidores, es más grande, más alto, más noble... el salvamento es y debe ser la consecuencia lógica de la natación. Consideramos al salvamento deportivo como un deporte completo, ya que, a las exigencias de tipo físico, cognitivo y afectivo, se les añaden otro tipo de exigencias más difíciles de encontrar, pero también más buscadas, las humanitarias, que le aportan un carácter integral, al comprobar que todo lo que se hace puede servir de entrenamiento perfecto para la realización de rescates en agua: conocimiento práctico y dominio de relaciones emocionales frente al entorno físico y humano. Gusto por la 
acción y por la solidaridad. Sentido del esfuerzo y de la responsabilidad en cooperación con los otros. Acceso a la autonomía en la propia actividad, pretexto para una ayuda por parte de otro, confiriendo así la seguridad. (Cocu y Pelayo, 1993 p. 48)

Figura 2

Prueba física establecida por la RFESS en una piscina

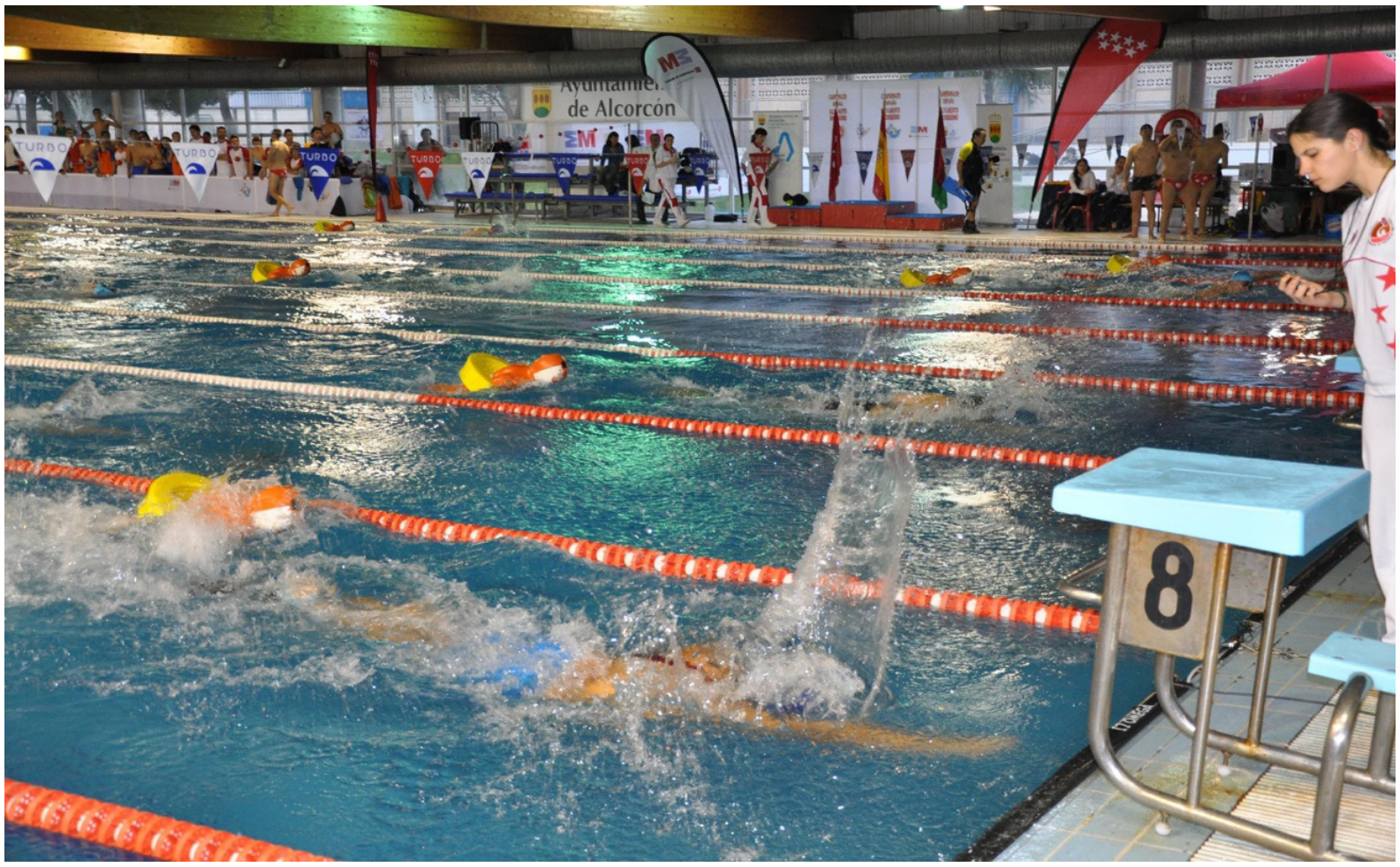

Nota. Fotografía cedida del archivo personal de uno de los miembros activos de la RFESS.

En las actividades y destrezas que impulsa esta Federación, vemos llevadas a la práctica e implícitas las siguientes palabras de Coubertin:

\begin{abstract}
El deporte es una de las "formas de la actividad", cualidad que no depende ni de la inteligencia ni de la salud, y que está lejos de ser universal, pero a la que la civilización moderna sirve de aguijón, procurándole múltiples ocasiones de emplearla. (Coubertin, 1901, p. 132)
\end{abstract}

Sin embargo, y al igual que ocurre en todos los deportes, la modalidad deportiva de Salvamento y Socorrismo también busca el espectáculo y la mejora del rendimiento deportivo. Por ello, el reglamento de competición de esta modalidad está asumiendo una serie de cambios y transformaciones que permiten que las técnicas, tácticas y estrategias empleadas por sus deportistas durante la competición, no siempre puedan ser extrapolables o aplicables a los rescates reales. En este sentido, algunos autores afirman que las modificaciones que se han ido realizando en los últimos años en el reglamento internacional de competición de este deporte, fomentan que se priorice la velocidad de ejecución de sus pruebas, frente a los criterios de seguridad y eficacia que se requieren en un rescate acuático real. Consecuentemente, estos mismos autores opinan que se podría llegar a comprometer el objetivo principal que motivó la creación de este deporte, que lo convierte en único. Es decir, un deporte que desarrolla la competencia de sus deportistas para salvar las vidas de los demás (Sánchez Fernández, 2007; Stallman y Hindmarch, 2012).

No obstante, a pesar de que algunas de las técnicas que emplean sus deportistas en las competiciones actuales no son aplicables a los rescates reales, también se quiere hacer constar que, en esta modalidad deportiva, se siguen aprendiendo multitud de competencias válidas e imprescindibles para resolver ahogamientos. De hecho, sus deportistas dominan desde edades muy tempranas, las habilidades y destrezas del salvamento acuático (nado de aproximación, traslado de víctima, buceo, etc.) así como el manejo de los materiales de rescate (tubos y tablas de rescate, aletas, etc.) que se requieren en los rescates acuáticos 
reales. Al mismo tiempo, la práctica de este deporte permite desarrollar la competencia en el agua y la condición física de sus practicantes, factores que la bibliografía especializada considera clave para incrementar las posibilidades de éxito en los rescates acuáticos: disminución del tiempo del rescate acuático, menor duración de la apnea e hipoxia de la persona ahogada, inicio más temprano y en mejores condiciones de las maniobras de resucitación y, por último, disminución del riesgo que asume la persona que realiza el rescate acuático (Abelairas Gómez, Romo Pérez y Barcala Furelos, 2013; Macintosh y Austin, 2013; Martínez y Hooper, 2014; RFESS, 2020c; Sanz-Arribas, 2018; Szpilman et al., 2014). Además de lo anterior, con la finalidad de que todos los participantes de este deporte sepan cómo realizar un rescate acuático real, la Normativa de Competiciones de la RFESS (2020d) establece que, para poder inscribirse en las competiciones oficiales organizadas por la RFESS, todos y todas las participantes mayores de 15 años deberán acreditar que están en posesión del diploma de socorrista o del taller monográfico de prevención en la práctica deportiva de Salvamento y Socorrismo, ambos expedidos por dicha institución.

\section{El valor educativo del buen ejemplo. El éxito del deporte y la manipulación mediática. Los ideales olímpicos como respuesta de la RFESS}

Todas las aportaciones positivas que puede proporcionar el deporte a la sociedad, debidamente orientado, alcanzan un valor añadido, que se hace cada vez más imprescindible en nuestros días por el éxito mediático que alcanza el deporte. Si ciertas actitudes, como las que implican los principios de la filosofía olímpica, son incorporadas por los deportistas como parte de su actividad deportiva, pueden cumplir el actualmente tan necesario: "valor educativo del buen ejemplo", que la Carta Olímpica actual recoge.

Los deportistas son hoy un foco especial de atención mediática. Se convierten en figuras cuyas actitudes y actuaciones son irremediablemente imitadas por una cantidad ingente de espectadores de todo el mundo. El valor educativo de su buen ejemplo puede estar elevado a la máxima potencia por el gran eco que los medios confieren a sus actuaciones deportivas. Merece una especial reflexión la ineludible responsabilidad social que recae sobre los deportistas "de éxito mediático", cuyo ejemplo de actuación deportiva, se presenta además asociado con demasiada frecuencia a los ingresos que percibe.

Es preocupante el triángulo: éxito deportivo, dinero y medios de comunicación. En ese ambiente el deporte se utiliza para alterar la escala de valores que permite convivir en paz y progresar positivamente al colocar al enriquecimiento como el verdadero éxito que debe priorizar. El enriquecimiento como el éxito a conseguir se inculca desde los medios de comunicación, dominados por ciertos sectores económicos. Esta escala distorsionada de valores utiliza el éxito del deporte para manipular las apetencias, conductas y formas de actuación de las masas, haciendo que ciertos deportes y deportistas de éxito mediático sirvan a sus intereses y no al bien colectivo.

Coubertin frente al avance de esos sectores que priorizaban el interés económico, se manifestó especialmente, proponiendo el deporte como la escuela práctica para ofrecer el "buen ejemplo" ya que el logro del éxito parte del esfuerzo y de la rectitud en los comportamientos:

En estos tiempos en que la sed de oro acumula tantos males, amenaza con comprometer las libertades [...] En estos tiempos en que la conciencia parece a veces perder sus derechos, es completamente necesario que se abra para la juventud una escuela práctica en la que se aprenderá que el éxito no se obtiene sino mediante voluntad y perseverancia, y no se consagra sino por medio de rectitud y lealtad. Esta escuela será el deporte. (Coubertin, 1920, p. 213)

Avanzando el tiempo advertía que la ambición económica desmesurada podría hacer perder al deporte su potencial positivo:

Los deportes se han desarrollado en el seno de una sociedad que amenaza con pudrirse hasta la médula a causa de la pasión por el dinero. Corresponde a las sociedades deportivas el dar ahora el buen ejemplo de una vuelta al culto al honor y a la sinceridad, desechando de sus recintos la mentira y la hipocresía. (Coubertin, 1925, p. 160) 
El día en que el deportista deje de poner por encima de toda la alegría de su propio esfuerzo, y la embriaguez de poder y equilibrio corporal que de él se deriva: el día en que se deje dominar por las consideraciones de la vanidad o de interés, ese día su ideal se acabará y el valor pedagógico de este ideal, si se puede emplear esta expresión, disminuirá irremediablemente. (Coubertin, 1920, p. 213)

Es imprescindible evidenciar que el ser humano ha evolucionado irremediablemente por la imitación de las conductas de sus congéneres, lejanos y cercanos. Hemos evolucionado repitiendo las conductas beneficiosas para el colectivo, rechazando otras actuaciones perniciosas para las personas y los grupos. Sin ese orden de valores, en cuanto a priorizar el bien común, nuestra especie ni siquiera hubiera tenido posibilidades de subsistir. Son las actuaciones del grupo que benefician al colectivo lo que ha permitido que ocupemos el lugar privilegiado que ocupamos en este planeta. Es imprescindible reflexionar sobre las conductas y actitudes que aprovechando la presencia del deporte en nuestra cotidianeidad se nos difunden todos los días, calando en los comportamientos que se imitan, perjudiciales para el avance positivo y la convivencia pacífica.

Ante la comprobación de la permeabilidad del individuo a las influencias de los "supuestos líderes" de su grupo social, ya Coubertin expresó sus miedos visionarios ante aquella sociedad de finales del siglo XIX en que los medios de comunicación empezaban a ser "el cuarto poder" y difundían ciertas conductas. El "valor educativo del buen ejemplo" que proporciona la práctica deportiva como hábito cotidiano, es un ejemplo práctico de lo que, con él se aprende. En palabras de Coubertin, debe quedar bien patente que el éxito no es el dinero, "que el éxito no se obtiene sino mediante voluntad y perseverancia, y no se consagra sino por medio de rectitud y lealtad" (Coubertin, 1920, p. 213).

La consciencia de la repercusión que alcanzan las conductas deportivas está bien patente en el Reglamento General de la RFESS, que incluye las siguientes advertencias y reflexiones en su Código de Conducta:

Los campeonatos son actos donde acude gran cantidad de público. La RFESS espera que todos los asistentes (competidores, técnicos, acompañantes, árbitros y público en general), cooperen en asegurar una buena imagen. Ante comportamientos que causen situaciones embarazosas o dañen la imagen de la RFESS y/o de la entidad organizadora, el Jefe de Competición, podrá tomar la decisión de expulsar a los competidores o a todo el equipo completo de la competición. (RFESS, 2019, p. 10)

También se alude a la "responsabilidad social", que alcanzan los comportamientos, de los deportistas mencionando explícitamente el "valor educativo del buen ejemplo":

Los miembros de un equipo representan a su país, a su federación, a su club, a sus patrocinadores y a la RFESS. Como tal, todos los miembros del equipo deberán en todo momento comportarse de manera apropiada, tanto en el campeonato como en las actividades alternativas que se organicen, entre las que se incluyen los actos sociales. (RFESS, 2019, p. 9)

Los competidores actuarán de acuerdo con las reglas y el espíritu de la competición. Aceptarán la decisión de los árbitros y jueces sin cuestionar ni quejarse fuera de las vías establecidas en el propio reglamento de competición al respecto. Nunca harán uso de drogas ni de cualquier otra sustancia o medio prohibido, para estimularse y así mejorar sus actuaciones. Su actuación será tolerante en todo momento. Aceptarán el éxito y el fracaso, la victoria y la derrota con elegancia y magnanimidad. Tratarán al resto de equipos y competidores con respeto, tanto dentro como fuera de la competición. (RFESS, 2019, p. 11)

El éxito deportivo presentado con demasiada frecuencia como paralelo a ingentes ganancias, incita hacia conductas irresponsables individuales y colectivas. Utilizando a los deportistas como instrumentos de su manipulación, se difunde la disculpa hacia conductas inaceptables, justificadas por el éxito del resultado deportivo, que en paralelo se identifica con el económico. Eso, ha llevado, a nivel individual a muchos deportistas, a ser irresponsables con su salud y denigrar su existencia, perdiendo la dignidad y sumergiéndose en ambientes que no les admiran, sino que les manipulan. Pero, socialmente, este paralelismo, "éxito igual a dinero", calando día a día en la cotidianeidad, no solo atenta a la libertad, sino que lleva a encauzar y justificar ciertas formas de actuación, presentes en el deporte mediático, en pro solo de intereses perniciosos inculcados furtivamente. Así, actualmente, en los países de nuestro entorno, con 
la máxima sensación de libertad, los poderes fácticos que manipulan la sociedad de consumo han conseguido que, demasiado frecuentemente nos comportemos en palabras de Coubertin como "borregos". Aceptamos lo inaceptable y lo perjudicial para todos, justificándolo por las ganancias. En nuestros días, a pesar de creer que actuamos bajo nuestras propias apetencias, casi inconscientemente, estamos siendo manipulados por los intereses "económicos", obedeciendo y comportándonos según se nos marca. Nos llevan a tener idénticos gustos, vestir, comprar y hacer las mismas cosas y tener similares comportamientos en los que ser "agresivo" evidencia inteligencia y éxito. A poco que observemos y reflexionemos sobre nuestra realidad cotidiana se evidencia una falta de libertad impuesta. Para ello, son utilizados con frecuencia los "deportistas de éxito mediático", cuyo esfuerzo y rentabilidad en el resultado deportivo se presenta paralelo sus ingresos; no se muestra como fruto del esfuerzo, de la constancia y de la honradez ¿Cuántos de nuestros niños quieren ser un deportista de éxito a quien tristemente se le conoce también, no solo por ser un ciudadano impresentable, sino por repetir conductas deportivas que no son precisamente "un buen ejemplo"?

Es imprescindible contestar el planteamiento egoísta y miserable de sectores que imponen el valor del éxito asociado exclusivamente al interés económico, tan mezquino y denigrante a nivel personal, humano y social y que está manipulando los comportamientos cegados de muchos sectores vulnerables. Hoy en día "el valor educativo del buen ejemplo", que puede proporcionar el deporte, se hace más sólido con el valor moralizante, resaltado con insistencia por Coubertin, como en una conferencia sobre la "Educación Inglesa", afirmando: "el rol que allí juega el deporte es un rol a la vez, físico, moral y social” (Coubertin, 1887, p. 135)

El valor que hoy alcanza "el buen ejemplo" debe ser utilizado por los individuos como personas, por los propios deportistas en beneficio de toda la sociedad, como hemos visto que advierte la RFESS a todos los implicados en sus actividades deportivas. Los deportistas pueden utilizar, desarrollar y mostrar en su día a día, el gran valor que supone una conducta solidaria, honesta y limpia, poniendo por delante la propia dignidad, la honradez, el buen hacer y la calidad humana que es el verdadero triunfo. Ese triunfo que el deportista de éxito actual sin duda ha alcanzado a partir del esfuerzo y la constancia que implica el deporte como forma de vida. Los propios deportistas son los más adecuados para compensar otro tipo de “ejemplos" impulsados por colectivos, a veces bien cercanos al deporte, que usan el deporte y con mucha frecuencia a los deportistas, con otros fines menos positivos y nada constructivos para todo el colectivo social $^{4}$. Se trata de situar claramente la escala de valores que realmente importa a los individuos y a los colectivos, de compensar la tendencia perniciosa de asociar el triunfo con la adquisición lucrativa ante lo que todo vale. La búsqueda del necesario sustento es imprescindible; pero no debe confundirse con la ambición desmesurada por el incremento económico. Lo que realmente nos hace progresar y superarnos, a nivel individual y social, no se adquiere con dinero; lo que nos hace progresar y evolucionar como personas se logra en el mismo ámbito y proporción del propio esfuerzo que se emplea. En esta línea, Coubertin exponía: "la práctica deportiva no produce igualdad de condiciones, pero sí la igualdad de relaciones (Coubertin, 1913, p. 120).

\section{La convivencia pacífica a partir de la competición deportiva}

El paralelismo entre la obra de Coubertin, y la práctica deportiva para el fomento de la paz, la amistad y la orientación de las rivalidades ha quedado demostrado por la bibliografía (Martínez Gorroño, 2012; 2014; 2019; Martínez-Gorroño y Hernández-Álvarez, 2014). En este sentido, el deporte fomenta el espíritu de superación personal. Es su "función agonística" (Hernández Álvarez, 1994), lo que supone el acicate de la rivalidad. Pero la rivalidad debe entenderse para contribuir al progreso humano, y compatibilizarse con su "función anatómico-funcional" (Hernández Álvarez, 1994); es decir, no puede ser reducida a saltar más alto, ir más veloz, ser más fuerte o ser quien más dinero gane. La orientación de la práctica deportiva debe ver al rival, al que te supera, como el compañero que puede enseñarte a superarte. Esa es

\footnotetext{
${ }^{4}$ No resistimos la tentación de citar aquí al fabuloso deportista español Rafael Nadal. Su trayectoria es un gran ejemplo mundial de la calidad humana que ha alcanzado y que le ha proporcionado el deporte, debidamente orientado desde su juventud. Personifica el "valor educativo del buen ejemplo” y es el orgullo del país.
} 
su potencialidad pacífica: "espíritu de amistad y juego limpio". Los ideales y la filosofía olímpica están enfrentados a esa visión estrecha de ver la superación personal a partir de la humillación del rival; visión mezquina y humillante para ambos contendientes, que lleva a la denigración de la calidad humana del supuesto triunfador y a la humillación y retroceso de todo el colectivo que lo acoge y lo permite, no digamos del colectivo que lo justifica y lo potencia.

La violencia en el deporte justificada como parte de la rivalidad y el triunfo deportivo es un tema especialmente preocupante. Los medios de comunicación parecen incidir en forma definitiva en difundir, cuando no en potenciar, las actitudes deportivas violentas, cuando se utilizan para conseguir el éxito deportivo, porque disparan las audiencias en pro de sus rentabilidades egoístas, malintencionadas y plagadas de insensatez.

Sin embargo, el deporte es un instrumento de gran utilidad para educar en la rivalidad positiva en armonía con la convivencia pacífica. Educando en la rivalidad bien orientada se aprende a competir y compartir, a ganar y a perder positivamente y a aprender de ambas, como en la vida. Esto es esencial para convivir pacíficamente en nuestra sociedad, que fomenta la rivalidad en todos los ámbitos. Con ese objetivo Coubertin concibió los Juegos Olímpicos. Aseguraba que, si los jóvenes de todos los países convivían en la Villa Olímpica, y compartían sus deseos de superación en competiciones pacíficas y sanas, sería más difícil que se les manipulara para contender en guerras matándose unos a otros. Guerras siempre escudadas en argumentos nacionalistas, de salvación de diferente índole, que solo contienen ansias de poder de minorías sórdidas, locas y miserables. En palabras de Coubertin:

Es preciso que, cada cuatro años, los Juegos Olímpicos restaurados, den a la juventud universal la ocasión de un reencuentro dichoso y fraternal, con el cual se disipará poco a poco esta ignorancia en que viven los pueblos, unos respecto a los otros, ignorancia que mantiene los odios, acumula los malentendidos y precipita los acontecimientos en el destino bárbaro de una lucha sin cuartel. (Coubertin, 1894, p. 23)

Tras la Primera Guerra Mundial, reflexionaba sobre la tergiversación de la escala de valores que movilizó masas y ocasionó tremendas tragedias. Proponía de nuevo al deporte como alternativa, siempre que fuera orientado adecuadamente:

En estos tiempos en que la sed de oro acumula tantos males, después de haber provocado el infame holocausto, amenaza con comprometer las libertades conseguidas por el valor y el heroísmo de los que fueron sus víctimas; en estos tiempos en que la conciencia parece a veces perder sus derechos, en que la devoción a la palabra parece debilitarse, es completamente necesario que se abra, para la juventud, una escuela de caballerosidad práctica, en la que se aprenderá que el éxito no se obtiene sino mediante la voluntad y perseverancia, y no se consagra sino por medio de rectitud y lealtad. Esta escuela será el deporte. (Coubertin, 1920, p. 213)

\section{Conclusiones}

El ideario olímpico, la idea y la práctica de utilizar el deporte como instrumento y elemento de paz y educación para los valores y actitudes que pueden contribuir al progreso es una realidad presente en el deporte español actual. La misión, visión y valores de la RFESS, junto con la modalidad deportiva del Salvamento y Socorrismo cumplen con este rol y, además, recogen el testigo de humanistas como Coubertin y de tantas gentes de bien que buscaron el avance positivo y la evolución de los seres humanos. Los deportistas de esta Federación, sus impulsores en el pasado y sus gestores actuales cumplen con el rol que la sociedad necesita: ofrecer su cooperación, su solidaridad y su esfuerzo altruista en beneficio de todo el que pueda necesitarlo. Ofrecen con sus prácticas el buen ejemplo que hoy estamos precisando para compensar otros ejemplos deportivos insistentemente aleccionados por los medios de comunicación.

Los valores establecidos por la RFESS nos sirven de conclusión y resultado del objetivo que pretende demostrar este trabajo:

La RFESS asume el fortalecimiento del ideal olímpico mediante la adecuada divulgación de su espiritu y filosofía, como son la deportividad, el esfuerzo y la superación; la defensa y 
el estímulo de la promoción de la ética deportiva, la promoción de la mujer en el deporte, de la igualdad de género y de oportunidades; defiende el juego limpio en un deporte que forma para salvar vidas, desde el compromiso y la solidaridad; apuesta por la colaboración con la sociedad, sus organizaciones y las Administraciones públicas [...] coloca a la formación como eje vertebrador de su afán diario para el enriquecimiento y desarrollo de la persona. (RFESS, 2020a, p. 2)

Por todo lo expuesto, nos parece especialmente interesante y conveniente que la modalidad deportiva de Salvamento y Socorrismo sea incluida en el contexto educativo. De este modo, todos los valores inherentes a este deporte podrían ser transmitidos en los centros escolares. Al mismo tiempo y, después de las evidencias presentadas en este trabajo, se considera que, la modalidad deportiva de Salvamento y Socorrismo posee una razón más para ser incluida en las competiciones olímpicas. Ello, no solo colmaría los anhelos de sus responsables; sino que serviría para demostrar en la práctica a los millones de espectadores de los Juegos, que los valores y los objetivos de la filosofía olímpica están vigentes y puestos en práctica por todos sus deportistas, inclinados a practicar un deporte cuyo objetivo es ayudar a todo el que lo necesite. Incluir en las competiciones olímpicas esta modalidad sería "el buen ejemplo", de las acciones que, entrenadas como deporte, prueban que los objetivos que impulsaron a Coubertin a emprender lo que hoy es conocido como Movimiento Olímpico se siguen manteniendo. Su inclusión olímpica, aprovechando el éxito del internacionalismo de los Juegos, ampliaría enormemente "el buen ejemplo" que la modalidad deportiva Salvamento y Socorrismo está dando.

\section{Agradecimientos}

Buena parte de las fuentes primarias necesarias para la elaboración de este estudio han sido facilitadas por la Real Federación Española de Salvamento y Socorrismo. Por lo tanto, en este apartado se agradece la inestimable colaboración de esta entidad y de su equipo profesional.

\section{Referencias}

Abelairas Gómez, C., Romo Pérez, V. y Barcala Furelos, R. (2013). Efecto de la fatiga física del socorrista en los primeros cuatro minutos de la reanimación cardiopulmonar posrescate acuático. Emergencias, 25, 184-190.

Abraldes, J. A. (2004). Salvamento acuático deportivo. Un deporte solidario. Xaniño Editorial.

Angueira, G. (1998). Salvamento deportivo. En J. Palacios, O. Iglesias, J. Zanfaño, J. Angueira y E. Parada (Eds.), Salvamento acuático, salvamento deportivo y psicología (pp. 251-298). Xaniño Editorial.

Calle-Molina, M. T. y Martínez Gorroño, M. E. (2014). Presencia o ausencia de los valores del movimiento olímpico en el currículo español de educación secundaria obligatoria en educación física: Un estudio de dos casos. Citius, Altius, Fortius: Humanismo, Sociedad y Deporte, 7(1), 99-121.

Cocu, P. C. y Pelayo, P. (1993). El salvamento: Objeto de enseñanza en el medio escolar. Revista de Educación Física: Renovar la Teoría y Práctica, 50, 41-48.

Comité Olímpico Internacional - COI. (2019). Carta olímpica vigente a partir del 26 de junio de 2019. Comité Olímpico Internacional.

Coubertin, P. (1887). L'Éducation anglaise. Les Études Sociales, 137, 125-144.

Coubertin, P. (1889). Atletismo y gimnasia. En N. Müller y J. A. Poyán Díaz (Eds.), Pierre de Coubertin 1863-1937. Olimpismo. Selección de textos (pp.128-130). Comité Internacional Pierre de Coubertin.

Coubertin, P. (1894). El atletismo en el mundo moderno y los juegos olímpicos. En INEF (Ed.), Ideario olímpico (pp. 19-24). Editorial Doncel.

Coubertin, P. (1901). Notes sur l'éducation anglaise publique. Hachette.

Coubertin, P. (1913). Le sport et la question sociale. Revue Olympique, 8, 120-123. 
Coubertin, P. (1918). Lettre olympique VIII. La Gazzette de Lausanne, 341, 1-2.

Coubertin, P. (1920). El deporte es rey. En N. Müller y J. A. Poyán Díaz (Eds.), Pierre de Coubertin. Olimpismo (pp. 212216). Comité Pierre de Coubertin.

Coubertin, P. (1925). Discurso pronunciado en el Ayuntamiento de Praga el 29 de mayo de 1925. En N. Müller y J. A. Poyán Díaz (Eds.), Pierre de Coubertin. Olimpismo (pp. 547-551). Comité Pierre de Coubertin.

EP. (25 de agosto de 2008). Los juegos olímpicos más vistos de la historia. El Confidencial. https://www.elconfidencial.com/comunicacion/2008-08-25/los-juegos-olimpicos-mas-vistos-de-las-historia_285226/

Federación de Salvamento y Socorrismo de Castilla-La Mancha-FSSCLM. (2017). Programa de formación de socorristas acuáticos de la federación de salvamento y socorrismo de Castilla-La Mancha. https://lasalamandrasiguenza.files.wordpress.com/2015/06/curso-soco-plan-docente.pdf

Hernández Álvarez, J. L. (1994). La educación física en el sistema educativo: Objetivos y contenidos. Evolución y desarrollo de las funciones atribuidas al movimiento como elemento formativo. Escuela Española.

International Life Saving - ILS. (2019). Competition rule book. International Life Saving Federation.

Macintosh, I. y Austin, S. (2013). Management of drowning in children. Paediatrics and Child Health, 23(9), 397-401. https://doi.org/10.1016/j.paed.2013.05.018

Martínez, F. y Hooper, J. (2014). Drowning and inmersion injury. Anaesthesia \& Intensive Care Medicine 15(9), 420423. https://doi.org/10.1016/j.mpaic.2014.06.006

Martínez-de-Haro, V., Sanz-Arribas, I. y Álvarez, M. J. (2019). El deporte, centro de interés del ser humano: Salud, cultura, ciencia, educación y ocio. Encuentros Multidisciplinares, 63, art 5.

Martínez Gorroño, M. E. (2012). El olimpismo y la paz. En M. E. Martínez Gorroño, y C. Durántez Corral (Eds.), Movimiento olímpico: Historia y retos actuales (pp. 29-54). Servicio de Publicaciones de la Universidad Autónoma de Madrid.

Martínez Gorroño, M. E. (2014). Les valeurs olympiques dans la réforme de l'éducation scolaire proposée par Pierre de Coubertin (1889-1937): Une éducation pour la paix, la liberté et la démocratie. International Olympic Academy.

Martínez Gorroño, M. E. (2019). Los valores olímpicos en la reforma de la educación escolar propuesta por Pierre de Coubertin (1889-1937): Una educación para la paz, la libertad y la democracia. Citius, Altius, Fortius: Humanismo, Sociedad y Deporte, 12(2), 15-25. https://doi.org/10.15366/citius2019.12.2.001

Martínez-Gorroño, M. E. y Hernández-Álvarez, J. L. (2014). La institución libre de enseñanza y Pierre de Coubertin: La educación física para una formación en libertad. Revista Internacional de Medicina y Ciencias de la Actividad Física y el Deporte, 14(54), 243-263.

O’ Farril, E. (1971). Salvamento y socorrismo. El deporte de la caridad. Deporte 2000, 25, 19-22.

Palacios, J. (1999). Salvamento acuático: Un estudio de la realidad del salvamento y socorrismo en las playas de Galicia con bandera azul 1996-1997 (Tesis doctoral). Universidade da Coruña, España.

Palacios, J. y Paredes, T. (1992). Salvamento acuático: Un deporte desconocido. Apunts. Educación Física y Deportes, 30, 46-56.

Palco23. (24 de agosto de 2016). Los JJOO de Río 2016 baten todos los récords de audiencia en TV e internet. Diario Económico Palco23. https:/www.palco23.com/marketing/los-jjoo-de-rio-2016-baten-todos-los-records-deaudiencia-en-tv-e-internet.html

Real Federación Española de Salvamento y Socorrismo - RFESS. (2016). Estatutos de la real federación española de salvamento y socorrismo. RFESS.

Real Federación Española de Salvamento y Socorrismo - RFESS. (2019). Reglamento general, jurado y normas de conducta. RFESS.

Real Federación Española de Salvamento y Socorrismo - RFESS. (2020a). Misión, visión y valores. RFESS.

Real Federación Española de Salvamento y Socorrismo - RFESS. (2020b). Credencial No122/2011 expedida por la Casa Real Española a la FESS por la que se le concede el título de "Real”. RFESS. 
Real Federación Española de Salvamento y Socorrismo - RFESS. (2020c). Informe nacional de ahogamientos: Muertes por ahogamiento en los espacios acuáticos españoles. Periodo 2015-2019. RFESS.

Real Federación Española de Salvamento y Socorrismo - RFESS. (2020d). Normativa de competición 2020/21. RFESS.

Sánchez Fernández, S. (2007). El salvamento acuático deportivo a estudio. En J. A. Abraldes y N. Rodríguez (Eds.), La particular relación entre el salvamento deportivo y su relación con el salvamento "profesional". Un caso único en el derecho deportivo (pp. 209-223). Federación de Salvamento e Socorrismo de Galicia.

Sanz-Arribas, I. (2018). Influencia de la longitud del vaso sobre las pruebas de socorrismo acuático profesional. Revista Internacional de Medicina y Ciencias de la Actividad Física y el Deporte, 18(72), 783-795. https://doi.org/10.15366/rimcafd2018.72.012

Stallman, R. y Hindmarch, T. (2012) Lifesaving competition: Speed \& safety. Conflict of interest? Revista de Salvamento Acuático y Primeros Auxilios, 37(4), 48-56.

Szpilman, D., Webberemail, J., Quanemail, L., Bierensemail, J., Morizot-Leiteemail, L., Langendorferemail, S. J., Lofgrenemail, B. (2014). Creating a drowning chain of survival. Resuscitation 85(9), 1149-1152.

https://doi.org/10.1016/j.resuscitation.2014.05.034

Yanes Vega, E. (2000). Comunicado personal enviado por Eladio Yanes Vega a la Federación de Salvamento y Socorrismo de Castilla y León en julio de 2000. RFESS.

\section{Breve CV de los/as autores/as}

\section{Ma Eugenia Martínez-Gorroño}

Doctora en Historia. Profesora de la Facultad de Formación del Profesorado y Educación de la UAM. Imparte docencia en el Grado de CCAFyD, en los Máster del Departamento de Ed. Física Deporte y Motricidad Humana y en el programa de Doctorado. Directora del Centro de Estudios Olímpicos de la UAM. Miembro de la International Society of the History of Physical Education and Sport (ISHPES) y de la Real Academia Olímpica Española. Miembro del "Grupo de Investigación de la Enseñanza y Evaluación de la Actividad Física y el Deporte” (GIEEAFyD). Directora de la revista "Citius, Altius, Fortius. Humanismo, sociedad y deporte: investigaciones y ensayos”. Representante de España y de la Academia Olímpica Española en las Sesiones de la Academia Olímpica Internacional (Grecia). En su línea de investigación sobre la historia de la Act. física y el deporte, ha presentado ponencias en congresos nacionales e internacionales y publicados trabajos en libros y revistas científicas nacionales e internacionales. Email: eugenia.martinez@uam.es

ORCID ID: https://orcid.org/0000-0003-0292-7558

\section{Ismael Sanz-Arribas}

Profesor del Departamento de Educación Física, Deporte y Motricidad Humana de la Universidad Autónoma de Madrid. Profesor del Grado y del Máster en Ciencias de la Actividad Física y el Deporte y del Máster en Actividades Físicas y Deportivas para la Inclusión Social de Personas con Discapacidad. Ha publicado diversos trabajos relacionados con la prevención del ahogamiento, la discapacidad, la salud en la actividad física y el aprendizaje y servicio. Responsable de la línea de trabajo "Educación para la prevención de ahogamientos y accidentes en el medio acuático” en la Cátedra UNESCO en Educación para la Justicia Social de la Universidad Autónoma de Madrid. Coordinador de las comisiones de Investigación y de Deporte Inclusivo de la Real Federación Española de Salvamento y Socorrismo. Inventor de un dispositivo denominado "prenda de baño salvavidas inteligente" que detecta y resuelve la pérdida de conocimiento en el agua. Email: ismael.sanz@uam.es

ORCID ID: https://orcid.org/0000-0003-1881-1955 


\section{$\mathbf{M}^{\mathbf{a}}$ Teresa Calle-Molina}

Maestra con la especialidad de Educación Física y Licenciada en CAFYDE. Doctora en Ciencias de la Actividad Física y el Deporte. Forma parte del Grupo de Investigación "Enseñanza y Evaluación de la Actividad Física y Deporte” (GEDAF) del Departamento de Educación Física, Deporte y Motricidad Humana de la UAM y participa en investigaciones relacionadas con la historia del deporte y la diversidad funcional. Miembro de la Red Nacional de Investigación en Aprendizaje-Servicio en Actividad Física y el Deporte para la Inclusión Social (RIADIS), participando en proyectos e investigaciones relacionados con el Aprendizaje-Servicio en el ámbito universitario. Forma parte del Centro de Estudios Olímpicos de la UAM colaborando en actividades académicas y educativas relacionadas con el olimpismo. Miembro de la Comisión de Deporte Inclusivo de la Real Federación Española de Salvamento y Socorrismo. Email: mariat.calle@uam.es

ORCID ID: https://orcid.org/0000-0001-7877-8283 